\title{
Pregabalin Abuse in between Jordanian Youths need to Concern
}

\author{
Dr. Maxim A. Obiesat ${ }^{1}$, Dr. Muath F. Marashdeh $^{2}$, Dr. Arafat K Al-Zoubi ${ }^{3}$, Dr. Malik M. Al-Alwan ${ }^{4}$, \\ Dr. Raya T. Al-Odat ${ }^{5}$ \\ 1,2,3,4 MD, Psychiatry, Jordanian Royal Medical Services, \\ 5 Pharmacists, Jordanian Royal Medical Services
}

\begin{abstract}
:
Pregabalin is a medication used extensively in neurosurgery and mental health care as it is sometimes used in primary health care in medical conditions but is increasingly reported as a potential increase of use leads to misuse and abuse. The fact, growing both levels of abuse and death; along with the growing nonmedical use has been reported in Jordan.

Objectives:

The main aim and cause of this study are to identify and evaluate cases of misuse or abuse from a database of Jordanian mental health care clinics. To identify the problem and the characteristics of the pregabalin, and to review the evidence base for this drug, try to find the answer if there is a need to worry about using this drug.

Methods:

All Pregabalin - (2016-2017) automated reports on misuse/ abuse/accreditation have been recovered. A descriptive-analytical report was performed
\end{abstract}

\section{Introduction:}

Pregabalin is a drug commonly used in deferent medical fields, extensively in neurosurgery and mental health care also sometimes used in primary health care in some medical conditions.

The strong association of pregabalin in the calcium channel leads to a reduction in excitation release molecules. In addition, it is believed that pregabalin possesses GABA simulated properties while this is possible direct or indirect effects on the dopamine reward system. Generally, pregabalin is characterized by higher efficiency, faster absorption rates, and greater bioavailability, although the pregabalin therapeutic doses may associate with low addictive responsibility.

Levels and misconceptions of these molecules to form a viable alternative to most common illicit drugs may be cause for concern. Pregabalin users are classified here as individuals with a record of misuse or abuse of substances and drugs (polydrug abusers) for recreational purposes, who treat doses clearly (eg up to 10 times) than those clinically recommended. Doctors consider describing Pregabalin should accurately assess the potential history of drug abuse when doctors suspect or fined signs of misuse or abuse of pregabalin because they have the ability to identify signs of misuse or use pregabalin immediately and provide possible help with clicking drugs.

\section{Results:}

From the Jordanian Mental health care clinics database 7639 male (6.6\% of a total of users) and 4301 females ( $4.8 \%$ of total users), the drug reaction reports of misuse/abuse/dependence were, related to pregabalin, with an overall reporting frequency increasing over time. For both genders, subjects typically involved were female adults.

About 7 deaths and 16 cases were reported to be diagnosed as drug-induced psychosis, with respect to pregabalin, often compensation with other substances was identified. The relative analysis of drug abuse/misuse/dependence appears to indicate that These adverse drug interactions were reported more frequently for pregabalin $(1.3,1.4$, and 1.6) compared to another gabapentinoids group. 


\section{Discussion:}

The study opens a deep overview of the problem of pregabalin misuse/abuse in Jordan.

From the point of view of those affected by abuse and dependency users reported increase efficacy and boosting the effect of pregabalin by combining it with other drugs and various sweet energy drinks. Different factors (e.g., lack of awareness about pregabalin abuse and pharmaceutical companies prospect for economic gain to income) complicate the role of medical staff in Jordanian communities. The poor of detection in urine screening and high coast of pregabalin level in blood test additionally facilitates abusers to continue on pregabalin. The poor of detection probably due to the variability of detection times of abused drug in urine, and differentiating new drug use from residual drug excretion could be difficult; it's harder after repeated or chronic usage.

\section{Conclusions:}

Despite data collection and policy constraints, the found data seem to suggest that pregabalin misuse/abuse is a cause for concern, especially in patients with a history of substance abuse or misuse.

So, healthcare professionals should be careful and cautious when prescribing pregabalin.

To consider prescribing pregabalin for neurological/psychiatric or other related disorders only and should be only by neurologist or psychiatrist or post their consultation with a medical report showing indications, duration of the expected management plan and regularly evaluate a possible misuse and provide possible assistance in tapering off the medication.

\section{References:}

[1] Baird, C. R., Fox, P., \& Colvin, L. A. (2014). Gabapentinoid abuse in order to potentiate the effect of methadone: a survey among substance misusers. PubMed

[2] Carrus, D., \& Schifano, F. (2012). Pregabalin misuse-related issues; intake of large dosages, drugsmoking allegations, and possible association with myositis: two case reports. PubMed

[3] Casati, A., Sedefov, R., \& Pfeiffer-Gerschel, T. (2012). Misuse of medicines in the European Union: a systematic review of the literature

[4] Cooper, R. J. (2013). Over-the-counter medicine abuse - a review of the literature. PubMed

[5] Driot, D., Chicoulaa, B., Jouanjus, E., Dupouy, J., Oustric, S., \& Lapeyre-Mestre, M. (2016). Pregabalin use disorder and secondary nicotine dependence in a woman with no substance abuse history. PubMed

[6] Drug Enforcement Administration, Department of Justice. (2005). Schedules of controlled substances: placement of pregabalin into schedule V. Final rule.

[7] Freynhagen, R., Backonja, M., Schug, S., Lyndon, G., Parsons, B., Watt, S., \& Behar, R. (2016). Pregabalin for the treatment of drug and alcohol withdrawal symptoms: a comprehensive review.

[8] Getto, C. J., Fullerton, D. T., \& Carlson, I. H. (1984). Plasma immunoreactive beta-endorphin response to glucose ingestion in human obesity.

[9] Grosshans, M., Lemenager, T., Vollmert, C., Kaemmerer, N., Schreiner, R., Mutschler, Hermann, D. (2013). Pregabalin abuse among opiate addicted patients.

[10] Haddad, L., Shotar, A., Umlauf, M., \& Al-Zyoud, S. (2010). Knowledge of substance abuse among high school students in Jordan. PubMed

[11] Hernandez, S. H., \& Nelson, L. S. (2010). Prescription drug abuse: insight into the epidemic.

[12] Holsti, O. R. (1969). Content analysis for the social sciences and humanities. Reading: AddisonWesley.

[13] Hughes, G. F., McElnay, J. C., Hughes, C. M., \& McKenna, P. (1999). Abuse/misuse of nonprescription drugs.

[14] Husserl, E. (1970). Logical investigation. New York: Humanities Press.

[15] Jaber, D., Bulatova, N., Suyagh, M., Yousef, A. M., \& Wazaify, M. (2015). Knowledge, attitude and opinion of drug misuse and abuse by pharmacy students: a cross-sectional study in Jordan.

[16] Johnson, B. A., Cloninger, C. R., Roache, J. D., Bordnick, P. S., \& Ruiz, P. (2000). Age of onset as a discriminator between alcoholic subtypes in a treatment-seeking outpatient population. PubMed

[17] Jordan Food and drug Administration (JFDA). (2014). Formal statement about the restricted dispensing of pregabalin in Jordan. Can be obtained from URL: 
Accessed June 11th 2016.

[18] Jordan Food and drug Administration (JFDA). (2017). Formal statement about the restricted dispensing of pregabalin in Jordan. Can be obtained from

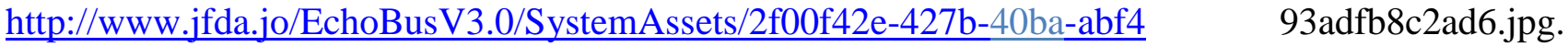
Accessed May 10th 2017.

[19] Kampov-Polevoy, A., Garbutt, J. C., \& Janowsky, D. (1997). Evidence of preference for a highconcentration sucrose solution in alcoholic men. PubMed

[20] Lessenger, J. E., \& Feinberg, S. D. (2008). Abuse of prescription and over -the-counter medications. PubMed

[21] Millar, J., Sadasivan, S., Weatherup, N., \& Lutton, S. (2013). Lyrica nights - recreational pregabalin abuse in an urban emergency department. Emergency Medicine Journal.

[22] Papazisis, G., Garyfallos, G., Sardeli, C., \& Kouvelas, D. (2013). Pregabalin abuse after past substance-seeking behavior PubMed

[23] Schifano, F., D’Offizi, S., Piccione, M., Corazza, O., Deluca, P., Davey, Mannonen, M. (2011). Is there a recreational misuse potential for pregabalin? Analysis of anecdotal online reports in comparison with related gabapentin and clonazepam data.

[24] Schjerning, O., Rosenzweig, M., Pottegård, A., Damkier, P., \& Nielsen, J. (2016). Abuse potential of pregabalin. PubMed

[25] Schwan, S., Sundström, A., Stjernberg, E., Hallberg, E., \& Hallberg, P. (2010). A signal for an abuse liability for pregabalin-results from the Swedish spontaneous adverse drug reaction reporting system. PubMed

[26] Spigset, O., \& Westin, A. A. (2013). Detection times of pregabalin in urine after illicit use: when should a positive specimen be considered a new intake? PubMed

[27] Van Hout, M. C., \& Hearne, E. (2017). User experiences of development of dependence on the synthetic cannabinoids, 5f-AKB48 and 5F-PB-22, and subsequent withdrawal syndromes. 